\title{
Actividad antibacteriana del extracto etanólico de Lessonia nigrescens Bory (Aracanto) frente a Staphylococcus aureus 6538 y Escherichia coli ATCC 8739
}

\author{
Jeans Darci Bocanegra Esteban ${ }^{1}$, Juana del Carmen Calderón Sánchez ${ }^{2}$
}

\section{Resumen}

Se evaluó la actividad antibacteriana del extracto etanólico de la macroalga marina Lessonia nigrescens frente a cepas bacterianas tipificadas. La obtención del extracto se realizó a través de la técnica de maceración, para determinar la presencia de metabolitos se efectuó tamizaje fitoquímico, y la actividad antimicrobiana se evaluó por medio de técnica de difusión en agar Kirby Bauer. Los resultados evidenciaron que L. nigrescens frente a Staphylococcus aureus ATCC 6538 muestra un halo de inhibición promedio de $8.52 \mathrm{~mm}$ y a Escherichia coli ATCC 8739 no muestra actividad; el tamizaje fitoquímico detectó la presencia de diversos compuestos, entre ellos fenólicos, esteroles, taninos y alcaloides. Concluyendo que el extracto etanólico de $L$. nigrescens Bory presentó actividad antimicrobiana únicamente frente a Staphylococcus aureus ATCC 6538, atribuyendo dicha propiedad a los metabolitos encontrados.

Palabras clave: Lessonia nigrescens, extracto etanólico, actividad antimicrobiana, tamizaje fitoquimico.

\section{Abstract}

The antibacterial activity of the ethanolic extract of the marine macroalga Lessonia nigrescens was evaluated against typified bacterial strains. The obtaining of the extract was done through the maceration technique, to determine the presence of metabolites phytochemical screening it was made, and the antimicrobial activity was evaluated by means of diffusion technique on Kirby Bauer agar. The results showed that L. nigrescens against Staphylococcus aureus ATCC 6538 shows an average inhibition halo of $8.52 \mathrm{~mm}$ and to Escherichia coli ATCC 8739 shows no activity; the phytochemical screening detected the presence of various compounds, including phenolic compounds, sterols, tannins and alkaloids. Concluding that the ethanolic extract of $L$. nigrescens Bory presented antimicrobial activity only against Staphylococcus aureus ATCC 6538, attributing said property to the metabolites found.

Keywords: Lessonia nigrescens, ethanolic extract, antibacterial activity, phytochemical screening.

\section{Introducción}

Desde la antigüedad hasta la fecha el ser humano ha empleado las algas como fuente de alimento por su contenido proteico y sales minerales. Sin embargo, investigaciones en los últimos años han llegado al interesante descubrimiento de su actividad, antioxidante, anti citotóxica, antiinflamatoria y antimicrobiana $^{(1)}$, de ahí su importancia para hacer frente al problema de salud global como es la resistencia bacteriana que se origina por mutación genética, traducida en la alteración estructural y en el mecanismo de inactivación de los agentes farmacológicos, de tal manera que se genera una disminución significativa de los fármacos antibacterianos capaces de combatir eficazmente a los microorganismos.
Hoy en día el uso de los recursos marinos con fines medicinales han cobrado mayor importancia y cada vez se incrementa el interés por investigarlas y el Perú no está ajeno a ello ya que posee una gran diversidad de flora marina a lo largo de nuestro litoral ${ }^{(2)}$ y cuenta con una amplia variedad de especies que han sido poco estudiadas o no tienen base científica que avalen sus propiedades ${ }^{(3)}$, como es el caso de Lessonia nigrescens, por lo que se debe realizar investigaciones orientadas a comprobar y verificar su potencial farmacológico antimicrobiano, de modo que represente una alternativa terapéutica natural capaz de eliminar ciertos agentes patógenos.

Por tal razón el presente estudio tiene como objetivo evaluar la actividad antimicrobiana del extracto etanolico de $L$.

\footnotetext{
${ }^{\prime}$ Químico Farmacéutico, Universidad Alas Peruanas (UAP). ${ }^{2}$ Licenciada en Biología, (UNMSM). ${ }^{2}$ Magister en Microbiología. Universidad Nacional Mayor de San Marcos (UNMSM). ${ }^{2}$ Docente del Departamento de Biología Celular y Molecular, Facultad de Farmacia y Bioquímica, Universidad Alas Peruanas (UAP).
} 
nigrescens frente a Staphylococcus aureus ATCC 6538 y Escherichia coli ATCC 8739.

\section{Material y métodos}

\section{Preparación del extracto etanólico}

Se recolectó $0.5 \mathrm{~kg}$ de alga Lessonia nigrescens en la estación de invierno, y se seleccionó frondas libres de plagas, las cuales fueron lavadas, luego secadas en estufa a temperatura de $40^{\circ} \mathrm{C}$ y finalmente pulverizadas.

El proceso de secado se realizó colocando las algas sobre papel Kraft, en estufa a temperatura de $40^{\circ} \mathrm{C}$, y se obtuvo algas totalmente secas. Luego se pesó y colocó $100 \mathrm{~g}$ de alga seca en un matraz de $500 \mathrm{~mL}$ y se agregó $500 \mathrm{~mL}$ de etanol al $96 \%$, previamente preparado, y se dejó macerar por 5 días, luego se filtró, finalmente el matraz se calentó en una cocinilla a $40^{\circ} \mathrm{C}$ durante 6 horas con la finalidad de evaporar el solvente, obteniendo un extracto de $100 \mathrm{ml}$.

\section{Marcha fitoquímica}

El extracto etanólico de Lessonia nigrescens para determinar la presencia de sus metabolitos, fue sometido a diferentes ensayos cualitativos los cuales fueron: Reacción con hidróxido de sodio, Reacción de Dragendorrff, Reacción de Legal, Reacción de Shinoda, Reacción de Liebermann Burchard, Reacción de espuma, Reacción con gelatina - cloruro de sodio y Reacción con cloruro férrico.

\section{Determinación de la actividad antibacteriana}

Para determinar la actividad antibacteriana del extracto etanólico de Lessonia nigrescens frente a cepas de Staphylococcus aureus ATCC 6538 y Escherichia coli ATCC 8739.

La actividad antibacteriana de los extractos etanólicos se evaluó empleando la técnica de difusión en agar (MullerHinton) aproximadamente $25 \mathrm{ml}$ a una temperatura de $45-50^{\circ} \mathrm{C}$ La siembra de las cepas bacterianas se realizó mediante el método de estrías en superficie y se colocaron los discos de papel filtro watman $\mathrm{N}^{\circ} 3$, impregnados con extracto etanólico a $20 \mathrm{mg} / \mathrm{ml}, 40 \mathrm{mg} / \mathrm{ml}, 60 \mathrm{mg} / \mathrm{ml}$ y $100 \mathrm{mg} / \mathrm{ml}$ respectivamente. Todos por triplicado.

Las placas se dejaron por 30 minutos a temperatura ambiente para permitir la difusión del extracto. Finalmente, las placas se incubaron a $37^{\circ} \mathrm{C}$ por 24 horas. Para evidenciar un halo de inhibición definido alrededor del disco lo que indicaba actividad antibacteriana positiva. La lectura de los halo se realizó empleando un vernier. Los valores obtenidos se promediaron hallándose el diámetro promedio que fue utilizado como índice de actividad antibacteriana.

\section{Resultados}

Tabla 1. En la marcha fitoquímica realizada al extracto etanólico de Lessonia nigrescens se determinó que contiene alcaloides, esteroles, saponinas, taninos y compuestos fenólicos.

La medida de cada disco es de $6 \mathrm{~mm}$, por lo tanto las muestras que tienen esta medición no evidencian efecto antimicrobiano.

Tabla 2. Muestra que el extracto etanólico de Lessonia nigrescens (Aracanto) presentó actividad antimicrobiana frente a Staphylococcus aureus ATCC 6835 con un promedio de $8.52 \mathrm{~mm}$ de halo de inhibición, frente a Escherichia coli ATCC 8739 no muestra halo de inhibición. Mostrando únicamente actividad antibacteriana contra el microrganismo Staphylococcus aureus ATCC 6538

\section{Discusión}

En el presente trabajo de investigación se realizó diversos ensayos para evaluar el efecto antimicrobiano del extracto etanólico de Lessonia nigrescens (Aracanto) sobre cepas de Staphylococcus aureus ATCC 6538 y Escherichia coli ATCC 8739 las cuales son de relevancia clínica por los mecanismos de resistencia antimicrobiana que desarrollan.

A pesar que se han hecho estudios acerca de las propiedades antibacterianas de Lessonia nigrescens (Aracanto) en diferentes lugares del mundo, cabe destacar que en nuestro país los estudios sobre este recurso vegetal son escasos, motivo por el cual es necesario profundizar en su estudio y dar a conocer sus posibles beneficios.

En nuestro trabajo el extracto etanólico de Lessonia nigrescens a las concentraciones de $100 \mathrm{mg} / \mathrm{ml}, 60 \mathrm{mg} / \mathrm{ml}$ y $40 \mathrm{mg} / \mathrm{ml}$ presentaron únicamente actividad frente a Staphylococcus aureus, tal como menciona Dania Andrea Di Filippo Herrera en la tesis titulada Variación de la composición

\begin{tabular}{|c|c|c|c|}
\hline \multicolumn{4}{|c|}{ Marcha fitoquímica del extracto etanólico de Lessonia nigrescens } \\
\hline METABOLITO & ENSAYO & RESULTADOS & OBSERVACIÓN \\
\hline Antocianinas & $\begin{array}{l}\text { Reacción con } \\
\text { hidróxido de sodio }\end{array}$ & - & No hubo reacción \\
\hline Alcaloides & $\begin{array}{l}\text { Reacción de } \\
\text { Dragendorrff }\end{array}$ & + & $\begin{array}{l}\text { Coloración rojo } \\
\text { ladrillo }\end{array}$ \\
\hline Lactonas & Reacción de Legal & - & No hubo reacción \\
\hline Flavonoides & $\begin{array}{l}\text { Reacción de } \\
\text { Shinoda }\end{array}$ & $=$ & No hubo reacción \\
\hline Esteroides & $\begin{array}{l}\text { Reacción de } \\
\text { Liebermann- } \\
\text { Burchard }\end{array}$ & + & $\begin{array}{l}\text { Formación de anillo } \\
\text { verde }\end{array}$ \\
\hline Saponinas & $\begin{array}{l}\text { Reacción de } \\
\text { espuma }\end{array}$ & + & $\begin{array}{l}\text { Formación de } \\
\text { espuma }\end{array}$ \\
\hline Taninos & $\begin{array}{l}\text { Reacción con } \\
\text { gelatina - cloruro de } \\
\text { sodio }\end{array}$ & +++ & $\begin{array}{l}\text { Precipitado denso } \\
\text { color blanco }\end{array}$ \\
\hline Fenoles & $\begin{array}{l}\text { Reacción con } \\
\text { cloruro férrico }\end{array}$ & + & Coloración púrpura \\
\hline
\end{tabular}

Leyenda: (+++) Reacción muy evidente, (++) Reacción evidente, (+) Reacción poco evidente, (-) No hubo reacción 




química y actividad biológica del alga café Sargassum horridum $^{(4)}$.

(Setchell \& n. L. Gardner, 1924) De la Bahía de la Paz, B.C.S., México, donde refiere que el extracto etanólico del alga Sargassum horridum de la jerarquía taxonómica Phaeophyceae misma de Lessonia nigrescens, mostró a la concentración de $2 \mathrm{mg} / \mathrm{ml}$ actividad antimicrobiana frente a las bacterias seleccionadas, siendo la especie más susceptible Staphylococcus aureus $^{(4)}$.

Los resultados de nuestro estudio no evidencian efectos antibacterianos frente a cepas de gramnegativas, datos que difieren del estudio realizado por Edra Jiménez, Fernando Dorta, Cristian Medina, Alberto Ramírez, Ingrid Ramírez y Hugo Peña-Cortés en la investigación titulada Actividades antifitopatogénicas de extractos de macro-algas, en la que señala que el extracto etanólico de Lessonia trabeculata, perteneciente al género del alga estudiada, tienen actividad antibacteriana únicamente a la concentración de $10 \mathrm{mg} / \mathrm{ml}(10 \%)$ frente a cepas patógenas gramnegativas enfrentadas, como Erwinia carotovora y Pseudomona syringae ${ }^{(5)}$. Esto posiblemente se debe a las condiciones climáticas de la costa chilena, lugar de recolección del alga, así como la estación del año en la que se obtuvo el recurso natural.

También se considera el método microbiológico (dilución en placas de 96 pocillos estériles) utilizado como factor influyente en el resultado final.

En el presente estudio se identificaron metabolitos que son considerados como posibles compuestos con actividad antimicrobiana como es el caso de los taninos precursores de los florotaninos y esteroles; entre los cuales se podrían encontrar fucosterol y/o saringosterol, que de acuerdo al trabajo realizado por Lino Lopes en la Tesis Algas marinas de la costa portuguesa: capacidad química, antimicrobiana $y$ antiinflamatoria, refiere que las macroalgas del filo Phaeophyceae contienen estos metabolitos y además a los florotaninos le atribuyen propiedades de interés médico; antibacteriano y antiinflamatorio ${ }^{1}$, así mismo en el estudio realizado por Muñoz Ochoa en la Tesis Potencial farmacológico de algas marinas de Baja California Sur, México, donde presenta datos del extracto etanólico de Sargassum horridum del filo Phaeophyceae que al ser fraccionado mediante cromatografía en columna se pudo aislar una molécula denominada fucosterol que además es un fitoesterol, el cual sería uno de los compuestos que presentó actividad frente a Mycobacterium tuberculosis ${ }^{(6)}$; por lo tanto se deduce que los esteroles podrían ser poseedores de propiedades antimicrobianas. También es de importancia mencionar la investigación realizada por Geral Wächter titulado Inhibición del crecimiento de Mycobacterium Tuberculosis por Saringosterol de Lessonia nigrescens, puesto que expone sus resultados que indican que el extracto del alga en estudio contiene esteroles entre ellos saringosterol ${ }^{(7)}$, metabolito a quien se le atribuye que posee actividad antituberculosa, lo cual se traduce en un amplio espectro antibacteriano.

\section{Conclusiones}

El extracto etanólico de Lessonia nigrescens (Aracanto), presenta actividad antimicrobiana únicamente frente a cepas patógena de Staphylococcus aureus ATCC 6538. Y esta propiedad se podría dar debido a la presencia de los metabolitos como saringosterol, florotaninos, fucosterol y a la sinergia de estos compuestos químicos.

\section{Referencias bibliográficas}

1.Lino LG. Seaweeds from the portuguese coast: chemistry, antimicrobial and anti-inflammatory capacity. [Tesis para optar el grado de Doctor en Ciencias Farmacéuticas, Fitoquimica y Farmacognosia especializada]. Porto: Universidad de Porto, Facultad de Farmacia; 2014.

2.Instituto Nacional de Salud [Internet]. Lima: INS; 2017 [Citado: 2017 Septiembre 19]. Disponible en: http://www.portal.ins.gob.pe en/censi/censi-c4/plantas-medicinales/informacion-general-plantasmedicinales

3.García GA, Gutiérrez ML, Acedo FE, Burgos HA, López TM, Valdés CM, Burboa ZM. Las algas y otros organismos marinos como fuente de moléculas bioactivas. [Publicación Periódica en línea] 2013 Enero [Citada 2017 septiembre 19] 15(1): 8pp. Disponible en https://biotecnia.unison.mx/index.php/biotecnia/article/view/132/125

4.Di Filippo H.D. Variación de la composición química y actividad biológica del alga café sargassum horridum (Setchell \& N. L. Gardner, 1924) de la bahía de La Paz, B.C.S., México [Tesis para obtener el grado de Maestría en Ciencias en Manejo de Recursos Marinos]. La Paz, B. C.
S: Instituto Politécnico Nacional, Centro Interdisciplinario de Ciencias Marinas; 2014

5. Jiménez E, Dorta F, Medina C, Ramírez A, Ingrid Ramírez,Hugo Peña-Cortés. Anti-phytopathogenic activities of macro-algae extracts. [Publicación periódica en línea] 2011 Mayo [Citada: 2017 Junio 24]; 15(7): [18pp]. Disponible en: www.mdpi.com/journal/ marinedrugs

6. Ochoa M. Potencial farmacológico de algas marinas de Baja California Sur, México [Tesis para obtener el grado de Doctor en Ciencias Marinas]. La Paz, B. C. S: Instituto Politécnico Nacional, Centro Interdisciplinario de Ciencias Marinas; 2010

7. Wächter GA, Franzblau SG, Montenegro G, Hoffmann JJ, William M. Maiese, Barbara N. Timmermann Inhibition of mycobacterium tuberculosis growth by saringosterol fron Lessonia nigrescens. [Publicación periódica en línea] 2001 Febrero [Citada: 2017 Junio 24]; 64(11): [2pp]. Disponible en: http://pubs.acs.org/doi/ abs/10.1021/np010101q?journalCode=jnprdf 